las formas inverosímiles de que se los reviste en las "visiones" del ingenioso satírico). En el período: "Todo era indicio de estómago en pena, de tripas en vacante y de hambreón descomunal", ¿qué puede ser hambreón sino un aumentativo de hambre, con retención de la vocal $e$ para distinguirlo del adjetivo hambrón, y por ende, qué sentido puede tener sino el mismo de 'hambre grande o extrema' que tienen las voces hambrina, hambruna y hambrusia? Aunque me parecía muy deseable explicar la expresión médico nordeste, como no se me sugirió ninguna aclaración que fuera posible confirmar, preferí no correr el riesgo de desorientar al lector con una solución que pudiese resultar falsa. La voz salina, ¿qué sentido puede tener sino el mismo que sal 'agudeza, donaire', cuando Torres dice, dirigiéndose a Quevedo: "Las festivas pimientas y tus abundantes salinas, cuando igualmente vestías la pluma de mojarrilla y de toga, ya no hay quien las guste"? La tuba lo mismo que la trompa es un instrumento de viento, y así no parece probable que a ningún lector general se le haga difícil entender por tubas falopianas los oviductos, que acostumbramos llamar trompas de Falopio.

Por fin, ninguno de cuantos alumnos he tenido, ni españoles, ni hispanoamericanos, ni angloamericanos, se ha confundido por el sentido de la expresión estornudos occidentales en el siguiente trozo de la descripción torresiana de un banquete de glotones, uno de los cuales "con el vendaval de un regüeldo, apagó una de las luces. Otro disparó mucha artillería de estornudos occidentales". Si yo' hubiese puesto un sabio escolio diciendo que "por lo visto no puede tratarse sino de una furiosa descarga de los que, con perdón del lector, en lenguaje vulgar, suelen apellidarse pedos o ventosidades y se producen por la repentina expulsión de los gases intestinales", ¿no habría merecido la crítica mucho más de lo que la merezco habiendo callado? Una nota sobre tal pasaje sería digna de un pedante de la categoría de ese famoso don Hermógenes, personaje de La comedia nueva de Moratín. ¡Cómo se habría reído también el mismo doctor don Diego de Torres Villarroel, siempre tan consumado artista de lo escatológico, si hubiese podido leer el "reparo" que me pone el reseñista por haber omitido comentar la "expresión nada fácil" de estornudos occidentales!

RusSEll P. SEbold

University of Pennsylvania.

\title{
ESTUDIOS SOBRE EL MODERNISMO *
}

Bajo el título Estudios críticos sobre el modernismo, Homero Castillo nos ofrece una recopilación de unos veinte textos críticos sobre el

* Acerca de los siguientes volúmenes:

Guillermo Díaz-Plaja, Las estéticas de Valle-Inclán. Gredos, Madrid, 1965. (BRH, Estudios $y$ ensayos, 85).

Ned J. Davison, The concept of modernism in Hispanic criticism. Pruet Press Inc., Boulder, Colorado, 1966. 
modernismo, escritos a lo largo de los últimos veinticinco años. Los problemas fundamentales son la cronología del movimiento, los autores que lo integran, sus fuentes y su definición. Sírvanos de guía este panorama de estudios críticos, si no completo, por lo menos básico para enfrentar interpretaciones opuestas todavía vigentes.

El primer artículo recogido por Castillo es el de Luis Monguró, "Sobre la caracterización del modernismo" (HCEC, 10-22). Su propósito es presentar el punto de vista de los primeros críticos del movimiento en cuanto a su definición. Según Monguió, la crítica está de acuerdo en una serie de rasgos: la cultura literaria de los creadores y su conciencia poética, el cosmopolitismo, el individualismo y el exotismo, la tarea de renovación métrica y la imitación extranjera. ¿Gultivaron el arte por el arte o fueron americanistas? Monguió toma partido por el esteticismo de los modernistas, lo que parece un tanto exagerado. En realidad el dilema no se plantea así. Vemos que dentro de la obra de un mismo poeta se da a la vez la tentación de una imposible torre de marfil y el inevitable compromiso en el tiempo y en la sociedad. Recordemos la famosa frase de Darío: "Yo no soy un poeta para las muchedumbres. Pero sé que indefectiblemente tengo que ir a ellas". El propio Luis Monguió, "El concepto de poesía en algunos poetas hispanoamericanos representativos" (HCEC, 83-117), tiene que apuntar que en Dario las ideas de poesía profética y de servicio público se vinculan con las de poesía dedicada a lo Bello gratuito. Por lo tanto, restringir la estética de Rubén Darío al único eje de la armonía, del amor por el arte, como lo hace también Raúl H. CAstagnino, " No soy más que un hombre de Artes" (RDER, 128-137), desfigura el genio del poeta. El pensamiento de Rubén Dario es esencialmente "pendular", oscila sin tregua entre la busca de lo Bello ideal y la responsabilidad cívica. Como prueba de ésta, fijémonos en la actitud espiritual de Darío con relación a los Estados Unidos. José Agustín Balseiro, "Rubén Darío y Estados Unidos" (en sus Seis estudios, pp. 117-143), у Pedro Morán OBıol, "Temática vital en Darío" ( $R D E R, 298-311$ ), analizan esta actitud. Para Balseiro, Dario se enfrentó con los Calibanes norteamericanos recurriendo a la Hispanidad $y$, en otras ocasiones, sostuvo el dinamismo político de la gran

María Esther Mangariello, Tradición y expresión poética en "Los romances de Rio Seco" de Leopoldo Lugones. Universidad Nacional de La Plata, Facultad de Humanidades y Ciencias de la Educación, Departamento de Letras, La Plata, 1966. (Monografias y tesis, 8 ).

Emilio Carilla, Una etapa decisiva de Dario (Rubén Dario en la Argentina). Gredos, Madrid, 1967. (BRH, Estudios y ensayos, 99).

José Agustín Balseiro, Seis estudios sobre Rubén Dario. Gredos, Madrid, 1967. (BRH, Estudios y ensayos, 103).

Rubén Dario: Estudios reunidos en conmemoración del centenario (1867-1967). Universidad Nacional de La Plata, Facultad de Humanidades y Ciencias de la Educación, Departamento de Letras, La Plata, 1968. (Tratados, comunicaciones y conferencias, 10$)$. -Abreviaré: $R D E R$.

Homero Castrllo (ed.), Estudios criticos sobre el modernismo. Introducción, selección y bibliografía por... Gredos, Madrid, 1968. (BRH, Estudios y ensayos, 121). -Abreviaré: HCEC.

Ivan A. Schulman y Manuel Pedro González, Marti, Dario y el modernismo. Con un prólogo de Cintio Vitier. Gredos, Madrid, 1969. (BRH, Estudios y ensayos, 127). 
nación, pero siempre admiró a poetas excepcionales como Poe. Sin embargo, parece que Balseiro sigue la interpretación tradicional de la «Salutación al águila». La conclusión del análisis de Morán Obiol (p. 305) acierta más al decir: "No hay, pues, renunciamiento en su actitud [de Darío], no hay cobardía, hay sí un anhelo metafísico de armonía y comprensión".

Precisamente quien insistió más, quizá por primera vez, sobre el aspecto "comprometido" del arte de Darío fue Pedro Salinas. En la selección de Castillo figura un trabajo suyo sobre "El problema del modernismo en España" (HCEC, 23-34). La tesis de Salinas opone el movimiento modernista a la generación del 98 . El modernismo se define como renovación poética, cosmopolita, sintética, ecléctica y abierta al mundo exterior. La generación del 98 quiere actuar sobre la conciencia nacional -y, más aún, castellana- con espíritu analítico y "ensimismado".

Comentando un verso de Machado: "Ni soy un av̀e de esas del nuevo gay trinar", Salinas afirma que la expresión "nuevo gay trinar" designa indudablemente al modernismo con sus "afeites" y su "cosmética". Puede creerse también con ANa María Lorenzo, "Rubén Darío y Antonio Machado" ( $R D E R, 453-483)$, la cual examina con gran detalle las relaciones de amistad entre ambos poetas, que la crítica de Machado tiene una índole más general. A semejanza de Darío, el poeta de Soria reprueba el preciosismo "no sólo en el modernismo sino también en el barroco literario, y en general en toda literatura" (p. 473). El problema queda planteado. Subrayemos, sin embargo, el "nuevo gay trinar" de Machado y otras expresiones del mismo poema: "la moderna estética", "la actual cosmética", que parecen dar la razón a Salinas.

Para FEDERico de ONís, el cual dio en 1934 la mejor definición posible del modernismo como movimiento de las sociedades europea y americana a finales del siglo xix, la revolución poética hispanoamericana y la generación del 98 son una sola cosa ("Sobre el concepto de modernismo", HCEC, 35-42). Onís se opone claramente a la tesis de Pedro Salinas. Nos preguntamos si esas opiniones no pudieran ponerse de acuerdo diciendo que modernismo y generación del 98 pertenecen a un mismo movimiento de renovación espiritual con dos realizaciones a veces opuestas. Así los puntos de convergencia y de diferencia se explicarían mejor que dentro de una oposición estéril.

Estamos asimismo de acuerdo con la mayoría de los matices y análisis individualizados que en el tratamiento del tema introduce RAFAEL FERRERES, “Los límites del modernismo y la generación del 98" (HCEC, pp. 43-65), salvo, como está indicado, con la interpretación dada al "nuevo gay trinar" de Machado. Por supuesto, Machado no rechaza el lenguaje poético de Rubén Darío, pero sí la afectación preciosista de cierto modernismo repudiado por el propio Darío.

Como ejemplo de las correspondencias entre la realización hispanoamericana y la española del movimiento general de finales de siglo, escojamos el caso de Valle-Inclán. La figura histórica de Rubén Darío aparece como personaje literario en Luces de Bohemia (véase el artículo de Patricio Esteve en $R D E R, 484-494$ ), prueba de la amistad cordial que unía a los dos escritores. Además, "las estéticas de Valle-Inclán" son, 
según el excelente trabajo de Guillermo Díaz-Plaja que lleva este título, claramente modernistas. Tanto en la visión mítica de la gloria pasada de Castilla como en la irónica concretada en Bradomín o en la degradadora de los esperpentos, Valle-Inclán sigue fiel a la voluntad de estilo característica del modernismo. Díaz-Plaja nos señala la afición de ValleInclán al hermetismo, a las corrientes filosóficas pitagóricas y al neoplatonismo correspondientes a ciertas tendencias simbolistas, rubenianas y modernistas, como se puede ver en los datos recogidos por Ricardo Gullón en su trabajo "Pitagorismo y modernismo" (HCEC, 358-383).

De cada página del libro de Díaz-Plaja surgen correspondencias entre Valle-Inclán y el modernismo, apuntadas o no por el autor. Véanse, por ejemplo, expresiones del libro de poemas El pasajero (1904) de pura cepa modernista, como "el cisne de la laguna", "mi barca de marfil", "la estela de la luna", "el hilo de plata sutil / de un cuento de las Mil y Una", etc. La "visión mítica" de Valle-Inclán se vierte en una "expresión poemática, de matiz musical, de acuerdo con los modos que Rubén Darío había introducido en la poesía y - no lo olvidemos- en la prosa bajo el dictado general de la literatura modernista" (Díaz-PlAJA, p. 188) . La afición de Valle a los temas arcaizantes, su valoración del pasado medieval y -añadimos nosotros-su culto por Wagner son también muy modernistas. Colombina, Arlequín y los palacios "de azules pensamientos", vienen de Verlaine a través de Rubén Dario, quien dio a ValleInclán otros esquemas estéticos (ibid., pp. 263-270) ${ }^{1}$.

A pesar de las afirmaciones de Guillermo Díaz-Plaja sobre el apoliticismo de Valle-Inclán, creemos que la evolución de su pensamiento en Tirano Banderas y El ruedo ibérico hacia un "colectivismo", es decir hacia el personaje-masa, corresponde a una progresiva politización (preocupación por el porvenir de la polis). El concepto de política manejado por Díaz-Plaja es demasiado estrecho, lo cual entraña contradicciones: si la sátira contra la patriotería, la sordidez, las palabras hinchadas, lo vacío, la condecoración externa, lo marcial no es denuncia, como lo pretende Díaz-Plaja siguiendo las huellas de Juan Guerrero Zamora, ¿qué será la denuncia? Pues este tipo de "política" integra plenamente el modernismo tal como lo entendemos, y tal como lo entendían Martí, Rodó, Darío a veces, y muchos otros.

Ahora bien, Guillermo Díaz-Plaja había defendido la radical diferencia del Modernismo frente a Noventa y Ocho. Cabía, pues, excluir a Valle-Inclán del 98 para no incurrir en otra contradicción. Y Díaz-Plaja lo excluye, en efecto, poniendo en duda la caracterización de Pedro Salinas: "Valle-Inclán, hijo pródigo del Noventa y Ocho". Tiene razón Salinas cuando añade: "Por el esperpento ingresa Valle-Inclán en el 98": como lo hemos visto, hay denuncia en la obra de Valle, denuncia que se une con su esteticismo modernista. El esteticismo, a su vez, es más que una técnica: es una verdadera Weltanschauung tanto como la del 98, pese a Dámaso Alonso y a Guillermo Diaz-Plaja y en conformidad con los juicios de Federico de Onís o de Ricardo Gullón, por ejemplo.

1 Una leve corrección al libro de Díaz-Plaja: como bien se sabe, Rubén Dario falleció el 6 de febrero de 1916 y no en el año 1917, como lo repite el crítico español en las pp. 214,259 y 267. 
En conclusión, puede decirse que el Valle-Inclán de Luces de Bohemia, al denunciar "la miseria del escritor tanto como la rebeldía del pobre obrero barcelonés que teme ser represaliado por la autoridad" (DíazPlaJA, p. 270, nota 19), realiza simultáneamente las actitudes del modernismo y del 98, tal como las realiza Unamuno, de quien dice el propio Díaz-Plaja (ibid., p. 273) : "sus criaturas de ficción aparecen siempre tan "literalizadas" como las de Valle-Inclán, cuyo transfondo libresco es tan fácil de deducir a primera lectura". Los caminos del modernismo y del 98 se cruzan una vez más merced al carácter hispánico del movimiento americano, que reivindica la unidad cultural de los pueblos de habla española (véase el trabajo de Donald F. Fogelquist, $H C E C, 66-74$ ) y culmina en la personalidad y obra de Rubén Dario, que influyó tanto en la literatura española del tiempo y admiró a hombres tan alejados de su mente como Unamuno (véase J. A. Balserro, "Rubén Darío y España", en sus Seis estudios, pp. 17-55).

Seguimos frente al dilema inicial con la contribución de EDMUNDo García Girón, "El modernismo como evasión cultural" (HCEC, 75-82) . Según este crítico, los modernistas se evaden de un mundo burgués que rechaza pagar el tributo a la literatura. Se refugian en la torre del Arte y anuncian la estética abstracta (es decir, no naturalista) de nuestro tiempo. Este tipo de explicación nos parece demasiado simplista y superficial. Plantea más problemas que los que resuelve. ¿Por qué, por ejemlo, no se rebelaron abiertamente los modernistas contra el ambiente burgués? ¿Es exacto, como lo afirma García Girón (p. 79), que los poetas fueron "indiferentes a los problemas sociales"?

Una vía más fructífera de indagaciones es la que sigue Allen W. Phillips, "Rubén Darío y sus juicios sobre el modernismo" (HCEC, pp. 118-145), el cual complementa el trabajo de Luis Monguió sobre la definición del modernismo por sus primeros críticos. Aquí se trata de estudiar las características del modernismo elaboradas por sus creadores. La palabra "modernismo" aparece por primera vez en Rubén Darío, con definición completa en el año $1890^{\circ}$. Pero dos años antes ya había publicado el poeta nicaragüense su programa estético en un artículo sobre Catulle Mendès. La estancia del poeta en Buenos Aires y en España confirma el empleo de la palabra, defendida hasta la muerte y matizada con elementos cada vez más íntimos. "Los prólogos de Darío" (véase la contribución de REYNa SuÁrez WiLson en RDER, 138-167) constituyen el mejor testimonio de la meditación estética sobre su propia creación poética. De ellos se desprende una poética completa, unitaria pero siempre abierta hacia el porvenir, y las variaciones de esta poética giran sobre un eje estético cuya expresión más clara es "El poema-prólogo a Cantos de vida y esperanza" (véase el artículo de María Luisa Punte en $R D E R$, 168-175). En este célebre "Yo soy aquel que ayer..." se unen la perfección formal y la interioridad humana del yo, su pasado, presente y

2 Señalemos de paso que la palabra "modernismo" designa también un movimiento de renovación religiosa en la Iglesia católica a principios de este siglo. No tiene nada que ver con el movimiento literario. Aquí Luis FARRÉ, "El modernismo religioso de principios de siglo" (RDER, 117-127), ensancha exageradamente el concepto de movimiento definido por Federico de Onis. 
porvenir. Sólo sentimos que la comentarista argentina haya dejado de lado "todo lo que teóricamente puede darse a la interpretación" de la estrofa (p. 174):

Y la vida es misterio, la luz ciega

y la verdad inaccesible asombra, la adusta perfección jamás se entrega, y el secreto ideal duerme en la sombra,

versos en los cuales aparece Darío como poeta que conoce con lucidez la imposibilidad de alcanzar la torre de marfil. Estamos lejos del escritor "puro", del "evadido cultural".

Sin embargo, esta tesis de la evasión cultural ha encontrado un defensor intransigente en Raúl Silva Castro. Para él, el modernismo es un movimiento literario que empieza en 1888 (fecha de $A z u l$ ) y acaba en 1916 (muerte de Dario). Se caracteriza esencialmente por el trabajo de la forma. Todo eso ha sido justamente rebatido, entre otros, por Manuel Pedro González e Ivan A. Schulman. La tesis de Silva Castro es erróneamente "dario-centrista" y abulta excesivamente el lado "escapista" del nicaragüense. Además, se apoya en el concepto un tanto estrecho de literatura como cosa muerta. Silva Castro busca pruebas de su interpretación general en detalles como el empleo del color azul por Rubén Darío. "El ciclo de «lo azul" en Rubén Darío" (HCEC, 146-167) es un ejercicio de estilística histórica. El azul, símbolo emocional de la vagancia artística, fue introducido en español por Rubén Dario, quien lo tomó sin duda de Victor Hugo ("L'Art, c'est l'Azur"), lo elaboró coherentemente entre 1886 y 1889 , manteniéndolo después, y lo escogió como paradigma del primer libro modernista. Contestando a Raúl Silva Castro en "Génesis del azul modernista" (HCEC, 168-189), Ivan A. SchulMAN llama la atención sobre los antecedentes del azul rubeniano en autores franceses y en José Martí. En efecto, la obra del cubano contiene varios ejemplos, anteriores a los de Darío, de un azul simbólico de lo etéreo, lo infinito. A los ejemplos franceses ya conocidos por los hispanistas, agreguemos algunos de Baudelaire, que en el poema "La Beauté» de Les fleurs du mal (1861) emplea la palabra azul con connotaciones de infinito, de ideal absoluto: "Je trône dans l'azur comme un sphynx incompris". Y también: "Des Cieux Spirituels l'inaccessible azur" ("L'aube spirituelle»); "Comme vous êtes loin, paradis parfumé, / Où sous un clair azur tout n'est qu'amour et joie..." ("Moesta et errabunda»). Y podríamos añadir otros más en que el azul se une al oro, otro color emblemático del modernismo. Pues, como lo subraya Schulman, el azul no es más que un color simbólico del cual se sirvió Martí a partir de 1875, Nájera desde 1876 y Darío por primera vez en 1884. Otros colores también importantes aparecen en la obra del propio Darío: el blanco, color predominante en Prosas profanas (véase Beatriz M. Guzmán, "Notas de color en Prosas profanas", RDER, 217-241), simbólico de la pureza, y el rojo, color de las pasiones. Todo eso ingresa perfectamente en "El lenguaje de la plástica", cuño estilístico no sólo de Rubén Darío 
(por lo que se refiere a éste, véase A. O. Nessi en $R D E R, 193-211$ ), sino de todos los poetas del movimiento ${ }^{3}$.

Pero el debate va mucho más allá de los problemas de colores. A la tésis restrictiva de Raúl Silva Castro -o, en otros términos, de Juan Marinello- se oponen resueltamente el mismo Ivan A. Schulman y Manuel Pedro González en su recopilación común de artículos, Marti, Dario y el modernismo, cuyo prólogo (escrito por Cintio Vitier) define perfectamente el propósito: el modernismo empieza no con Darío en 1888, sino hacia 1882 -quizá antes-con Martí *. Ello no quita nada a la gloria de Rubén, sino que lo coloca en su verdadero sitio. Así Martí no figura ya como "precursor", sino como modernista íntegro.

En sus "Reflexiones en torno a la definición del modernismo", ScHULMAN ensancha bastante los límites cronológicos e ideológicos del movimiento, considerado como proceso total de índole sincrética e individualizada. Creemos también que la amplitud del proceso rechaza toda fijación precisa de su principio o de su acabamiento. Podríamos afirmarlo de cualquier movimiento literario. Schulman encuentra influencia del modernismo hasta en la prosa de novelistas coetáneos, como Mario Vargas Llosa. Hay que añadir que estos novelistas quieren conscientemente cortar con el modernismo, tal como los modernistas querian "revolucionar" la palabra poética anterior. Se necesita la influencia modernista sobre ellos para explicar sus obras, pero negativamente o como preparación a su trabajo de re-apropiación del verbo castellano.

Enfocado de esta forma el problema general, se entiende mejor cómo Martí puede ingresar plenamente en el modernismo. La demostración la da, en lo esencial, Manuel Pedro González. Primero recoge los testimonios del prestigio de que gozaba Martí entre sus coetáneos. Hubiera podido añadir el del argentino Carlos Ramagosa, que el 15 de octubre de 1896 definía a José Martí como "la personalidad más original que ha producido la América" (véase J. A. BAlseiro, Seis estudios, pp. 52-53). De un estudio de interpretación biográfica se desprende claramente -y estamos de acuerdo con M. P. González- que Martí ofrece rasgos de cultura modernistas. Quizá hay algunos juicios demasiado apresurados sobre el valor de la prosa española anterior a Martí. No hay duda de que el cubano creó hacia 1882 una nueva prosa artística. Pero ¿carece la prosa de Pérez Galdós de preocupaciones estilísticas (p. 103) ? ¿No se adapta esta prosa a sus intenciones novelísticas (p. 105) ? No estuvo Galdós atento a todos los niveles de la lengua hablada por sus personajes (p. 109)? Galdós fue tan grande como Martí en el manejo de la lengua, pero en otro plano. No sirve para nada al mérito del cubano el desconocer que la lengua del español es función esencial de su arte novelístico.

Lo dicho no impide que en Martí haya "Conciencia y voluntad de estilo" (pp. 109-158). Lo demuestra con acierto M. P. GonzÁlez al ana-

3 Sobre otro símbolo modernista, véase el estudio de E. Figleroa Amaral, "El cisne modernista", HCEC, 299-315.

4 En HCEC, se leerá además: M. P. Gonzílez, "En torno a la iniciación del modernismo", pp. 211-253; I. A. Schulman, "Reflexiones en torno a la definición del modernismo", pp. 325-357 (este trabajo también en el libro de 1969, pp. 23-59). 
lizar páginas de Martí anteriores a 1882 (año de su auge literario), particularmente de 1877. Indudablemente aquí encontramos rasgos típicos de una prosa impresionista. Martí, pues, no fue "precursor" del modernismo sino auténtico creador, como lo fueron José Asunción Silva, Julián del Casal y Gutiérrez Nájera, otros pretendidos "precursores". La lectura de textos de teoría literaria escritos por Martí en 1881 muestra la conciencia crítica del cubano con relación a su propia obra de renovación estilística que iba a culminar en 1882 con sus crónicas para $L a$ Nación de Buenos Aires, Ismaelillo y una parte de los Versos libres. Por su estilo de pintor, más que de escritor, Martí es, según la expresión de M. P. González, "creador de la prosa modernista" y también de cierto impresionismo poético.

Acaban el libro dos estudios de Schulman sobre las relaciones de Martí con Darío. En el primero, "Resonancias martianas en la prosa de Rubén Darío (1898-1916)" (pp. 206-246), el crítico descubre procedimientos, giros y expresiones de procedencia martiana en Rubén Darío, a pesar de la radical diferencia del concepto de prosa que separaba a ambos escritores. Por desgracia, algunos ejemplos no convencen. EI polisíndeton (p. 226) y el estilo anafórico son procedimientos muy empleados en la prosa hispánica desde el Renacimiento, y no prueban la filiación Martí > Darío, como nunca lo hace este género de investigación de fuentes mediante analogías retóricas dentro de la misma época. Así también la estructura reiterativa de dos páginas de Martí y Darío (p. 236) no puede decirnos nada seguro acerca de una hipotética influencia del uno sobre el otro, y el $n i$ y el ya reiterativos (p. 240) son giros muy clásicos. Darío, lector de Martí, lo fue también de la Biblioteca de Autores Españoles de Rivadeneyra. La coincidencia retórica entre ambos escritores merece, pues, un estudio más detenido para que se pueda probar cualquier filiación. Más claro es el caso de «Marcha triunfal» y «Castelar» de Darío y «El centenario de Calderón» de Martí (pp. 247-257), porque además de rasgos estilisticos comunes, que pueden siempre proceder de una misma tradición, hay aquí una coincidencia temática que hace indudable el conocimiento directo y la imitación de Martí por parte de Darío ${ }^{5}$. En resumen, estamos convencidos, con Schulman, de este conocimiento e imitación ${ }^{6}$, pero nos quedamos con el problema del grado que tuvieron.

Una de las aportaciones más importantes de Manuel Pedro González e Ivan A. Schulman, ya lo hemos visto, es pasar por alto los límites cronológicos tradicionales del modernismo. También Bernardo GicoVATE cree que hay que ensancharlos. En un primer trabajo ("Antes del modernismo", HCEC, 190-202) describe el estado aislado y decadente de la cultura hispánica antes del modernismo. Por eso los modernistas

5 La prueba de lo difícil de estos argumentos de aproximaciones de textos la da J. A. Balseiro, que ve en los versos de Darío "¡Ya viene el cortejol" una influencia de sonoridades wagnerianas (!) ("Presencia de Wagner y casi ausencia de Debussy en la obra de Rubén Darío", en sus Seis estudios, pp. 57-71).

6 En otro plano siguió Dario el consejo de Marti: "para hablar bien nuestra lengua, no hay como conocer otras" (véase J. A. BALseiro, "Rubén Dario y la lengua inglesa" Seis estudios, pp. 103-116). 
tuvieron fatalmente que recurrir al extranjero. Sin embargo, siguieron fieles a aspectos de Campoamor, Bécquer (sobre todo) y algunos poetas hispanoamericanos hoy olvidados. En un segundo artículo, "El modernismo: movimiento y época" (HCEC, 203-210), Gicovate retrasa la fecha del principio del modernismo hacia 1880 y lo hace perdurar en algunos autores coetáneos. Repetimos lo dicho ya a propósito del "modernismo" de los nuevos novelistas hispanoamericanos. Pero hace bien Gicovate en afirmar una vez más que el modernismo es un movimiento total, liberalizador al principio, que desembocó en el vanguardismo de los años veinte. También era necesario decir firmemente que el modernismo dio el impulso imprescindible al nacimiento de una literatura hispanoamericana auténtica.

Sigue presente Luis Monguió en el libro de Homero Castillo con un estudio "De la problemática del modernismo: la crítica y el «cosmopolitismo»" (HCEC, 254-266), el cual toca un carácter fundamental del movimiento. No discutiremos más el hecho de que $A z u l$ sea o no la obra epónima inicial del modernismo. No lo es. Afortunadamente el prejuicio tradicional no hace desmerecer para nada el valor general del estudio, en el cual Monguió establece la estimativa del cosmopolitismo modernista. El cosmopolitismo, valor positivo para Rodó y los primeros críticos de Darío, se convierte en elemento negativo con pretexto de la moda "criolla". El enfoque que nos parece más correcto es el de Isaac Goldberg y Federico de Onís, para`quienes el cosmopolitismo de los modernistas participa del espíritu general de la época. Como bien se sabe, el cosmopolita por excelencia fue Rubén Darío. Su libro Los raros lo muestra ampliamente (véanse Roxana Gardes, "Lo raro en Los raros", RDER, 179-192, y M. C. Rezzano DF MARTINi, "Los raros y los escritores ingleses y norteamericanos", ibid., 315-328). Basta citar los modelos franceses de los americanos, incluyendo a los más olvidados, como Laurent de Tailhade y Armand Silvestre (véase E. TABERnig DE Pucciarelli, "Dos olvidados modelos franceses en los modernistas", $R D E R, 329-338)$. Arriba hemos visto un feliz encuentro entre el azur de Baudelaire y el azul modernista. Feliz encuentro y nada más. Algunos han creído descubrir en la obra de Darío reminiscencias baudelairianas. José María Ferrero ("Darío y Baudelaire", $R D E R$, 339-350), por ejemplo, compara "Invernal» de Azul con "Paysage» de Tableaux parisiens. A nuestro juicio, sólo se trata de coincidencias temáticas debidas a un ambiente generacional y a temperamentos semejantes. De todas formas, es muy curioso observar que Darío, tan prolijo en citar nombres de poetas que prefiere, nunca habla de Baudelaire.

Cosmopolita lo fue también Dario en sus investigaciones formales y métricas. Como lo muestra E. F. LonNÉ, "Aspectos de la versificación de Prosas profanas" (RDER, 242-290), esas investigaciones se vinculan con el Parnaso y el simbolismo francés. Cosmopolitismo en el espacio, pues, pero también en el tiempo. Darío alude muy a menudo a Grecia, a Roma, al siglo xviı francés, a dioses, héroes, ciudades "clásicas", y realiza una perfecta síntesis entre lo antiguo y lo moderno (véase A. J. VAcCARo, "Muy antiguo y muy moderno. Ecos clásicos", $R D E R, 212$ 216). El indigenismo o exotismo es otra forma de cosmopolitismo en 
reacción contra el mundo burgués. Tal es la tesis de Ricardo Gullón ("Indigenismo y modernismo", HCEC, 267-278; "Exotismo y modernismo", ibid., 279-298). Protestan los modernistas contra el presente mezquino y deshumanizado recurriendo al mito romántico del "buen salvaje". En este caso la busca de lo bello (estética) se confunde con la de la verdad (ética).

Quien resume mejor en su vida y obra esas características generales del modernismo es, evidentemente, Rubén Darío (véase O. A. FERnández, "Síntesis cronológica de la vida y obra de Rubén Darío, 1867-1916", $R D E R, 15-25)$. Cuando se emprende un ensayo de comprensión profunda de la vida del poeta desdramatizándola, como lo hace J. C. Ghiano en "La versión autobiográfica de Darío" (RDER, 29-63), se constata mejor cuánto representa Darío en la literatura hispánica, en la que ocupa un puesto imprescindible del que él mismo tuvo temprana conciencia.

En su vida fue importantísima la estancia en Buenos Aires (18931898) . Varios críticos dedican lo mejor de su talento a describirla. "Buenos Aires en 1890" era una ciudad que podemos calificar de "modernista". Esto se desprende del estudio de NeLba Benítez (RDER, 67-98), que completa sociológicamente el libro de Emilio Carilla, Una etapa decisiva de Dario (Rubén Dario en la Argentina) ${ }^{7}$ y el capítulo cuarto del de Balseiro, "Argentina, "región de la auroras" (en sus Seis estudios, pp. 89-102). Colaborador de La Nación, fundador de la efímera Revista de América, orador escuchado en las reuniones del Ateneo de Buenos Aires y otras sociedades culturales, Dario publica en 1896 Los raros y Prosas profanas y escribe otras obras aparecidas más tarde o recogidas en volúmenes póstumos. Allí también encontró a personas tan importantes en el desarrollo de la literatura argentina como Paul Groussac que, a pesar de sus críticas al movimiento y a los libros de Darío, acaba por reconocer el valor del poeta. Sobre todo fue en Buenos Aires donde reunió Dario por primera vez un verdadero grupo modernista, cuyas figuras más egregias fueron Jaimes Freyre y Lugones. Con el primero le unieron lazos de amistad muy sincera, como puede verse en la ayuda de Darío a la difusión española de Castalia bárbara. Dario conoció a Lugones en 1896, año clave para ambos. Inmediatamente elogió al poeta de Córdoba en un artículo de La Nación. A pesar de la ausencia de un retrato de Lugones en la galería de Los raros - lo cual provocó una reacción inquieta e indignada de éste-, siguieron los elogios recíprocos, que permiten caracterizar sus temperamentos esencialmente diferentes. Lo subraya muy bien María Esther Mangariello, "Rubén Darío y Leopoldo Lugones" (RDER, 373-387), autora también de un libro sobre Tradición y expresión poética en "Los romances de Río Seco" de Leopoldo Lugones, trabajo de indole descriptiva, sin comentarios explicativos profundos, salvo el último capítulo ("La expresión poética"), el único que justifica el título del libro. Esta presentación sencilla basta para dar al lector una idea general de Los romances de Rio Seco, de su sitio en la poesía épica de Lugones, de su temática, del medio reflejado y de los personajes.

i Extractos de este libro también en RDER, 99-114. 
Otros modernistas del grupo bonaerense merecen estudios detenidos a pesar del valor literario reducido de sus obras, comparadas con las de los preferidos de Darío. Tales son Ángel Estrada, que cultivó el Arte, lo Bello, la Forma antes de la estancia de Darío, novelista ultra-modernista de Redención (1906) (véase el artículo de A. C. Garat en RDER, 397418), y Carlos Ortiz, epígono "americanista" de Darío, asesinado por motivos políticos en 1910 (véase la contribución de D. A. M. DE ZACCARd, ibid., 419-452).

Así, pues, como lo subraya Emilio Carilla (Una etapa decisiva..., pp. 151-160), existía en la capital argentina de hacia 1890 un terreno favorable para la renovación literaria impulsada por Darío, terreno labrado ya por José Martí, colaborador también de La Nación entre 1882 y 1891. Esto, notémoslo de pasada, refuerza más aún la tesis de Manuel Pedro González e Ivan A. Schulman. Pero hay que reconocer que fue Darío quien dio el impulso necesario a las letras argentinas de finales de siglo. Con Emilio Carilla (pp. 161-174) podemos decir que los escritores de esa generación le debieron todo o, por lo menos, mucho.

La influencia de Darío siguió viva en la Argentina, como lo muestra muy bien J. Gómez Paz con el caso de Alfonsina Storni (RDER, 388396). Recíprocamente la Argentina influyó en la obra de Darío. Nunca olvidó el poeta a su transitoria patria de adopción. El paisaje de la pampa lo movió a escribir un poema, "Desde la Pampa» (de principios de 1898), excelentemente analizado por Emilió Carilla (Una etapa..., pp. 183-198). El tardío «Canto a la Argentina» testimonia aún los lazos que unían a Darío con este país (véase la paráfrasis de Zulema INÉs JORGE en $R D E R, 291-297$ ).

Una buena síntesis de todos los problemas básicos del modernismo que hemos tratado la constituye el libro de NED J. Davison, The concept of modernism in Hispanic criticism. Desde un principio los enfoca el autor en la perspectiva de Luis Monguió: su objeto consiste en recoger las ideas críticas sobre el modernismo y clasificarlas. Primero encuentra Davison un consensus (cap. 2, pp. 13-40), es decir, características muy admitidas por todos. Sin embargo, no creemos que la partición del modernismo en dos épocas, esteticismo y "mundonovismo", con fecha divisoria en 1895, corresponda a un topos crítico. No creemos, por ejemplo, que Manuel Pedro González e Ivan A. Schulman, o los que consideran el modernismo como movimiento total, compartan semejante idea. En lo que sigue, ofrece el crítico norteamericano una lista de los caracteres del movimiento conforme a la que da Luis Monguió en su artículo citado "Sobre la caracterización del modernismo". A la visión del modernismo como esteticismo (cap. 3, pp. 41-48), cuyo defensor principal según Davison es Juan Marinello, ya nos hemos referido también. Davison nos advierte que Marinello es marxista. Sólo diremos que una verdadera crítica sociológica y marxista va más allá de las apariencias, que emite juicios sobre el conjunto total de la forma del contenido -es decir, el estilo- y no únicamente sobre una forma o contenido.

En el capítulo "The epochal view" (cap. 4, pp. 49-56) reúne Davison los conceptos de Ricardo Gullón y Federico de Onís, opuestos a los de 
Juan Marinello, y, en cuanto a la vinculación del modernismo con la generación del 98, a los de Pedro Salinas y Guillermo Díaz-Plaja.

En su conclusión, "The future of the concept" (cap. 5, pp. 57-59), apunta que hasta ahora la mayoría de los críticos reflexiona a partir de la poesía de Rubén Darío. Es el "dario-centrismo" que denunciábamos, y del cual se desprenden dificultades serias para la comprensión de otros escritores. Necesitamos, pues, análisis de obras individuales para precisar mejor las características generales y, si es posible, los límites cronológicos.

En la bibliografía sobre el modernismo de Davison hay más obras de indole general que en la de Homero Castillo. Sin embargo, ésta es generalmente más amplia. Ambas juntas constituyen un instrumento de trabajo imprescindible.

Universidad de Lieja.

Jacques Joset 